\title{
Haemorrhoidal Disease in Cotonou: Epidemiological, Clinical and Anuscopic Aspects
}

\author{
Jean Sehonou ${ }^{1}$, Finangnon Armand Wanvoegbe ${ }^{2 *}$, Aboudou Raïmi Kpossou ${ }^{3}$, \\ Kouessi Anthelme Agbodande1, Roméo Dah-Bolinon'², Angèle Azon-Kouanou', \\ Marcel Zannou ${ }^{1}$, Fabien Houngbe ${ }^{1}$ \\ ${ }^{1}$ Unit of Internal Medicine in the National Teaching Hospital "HKM", Cotonou, Benin \\ ${ }^{2}$ Internal Medicine Unit, Departmental Hospital of Oueme Plateau of Porto-Novo, Porto-Novo, Benin \\ ${ }^{3}$ Unit of Hepato-Gastroenterology of the Hospital Menontin, Cotonou, Benin \\ Email: jsehonou@yahoo.fr, ’wafinarm@yahoo.fr, kpossou.raimi@yahoo.fr, agbotem@yahoo.fr \\ dahbolinonrustico@yahoo.fr, angele kouanou@hotmail.com, djmzannou@yahoo.fr, \\ fab2012jos@yahoo.com
}

Received 1 June 2015; accepted 12 July 2015; published 15 July 2015

Copyright (C) 2015 by authors and Scientific Research Publishing Inc.

This work is licensed under the Creative Commons Attribution International License (CC BY).

http://creativecommons.org/licenses/by/4.0/

c) (i) Open Access

\section{Abstract}

The haemorrhoidal disease is a very common disorder in proctology. It is favoured by many factors. Although benign, its treatment is difficult. Our aim is to study the epidemiological, clinical and anuscopic of haemorrhoidal disease. This was a cross sectional, descriptive and prospective study covering a three-month period from 06 January 2014 to 10 April 2014. It involved patients seen in gastroenterology consultation in internal medicine of the National Teaching Hospital of Cotonou and in the digestive diseases Unit of the Hospital of Menontin. We recorded 182 patients including 57 cases of haemorrhoidal disease, a prevalence of $31.3 \%$. The sex ratio was 1.10. The average age was 43 years with extremes of 18 and 88 years. Anal events were dominated by rectal bleeding $(54.4 \%)$ with a predominance of internal haemorrhoidal disease $(87.7 \%)$. Stage 2 evolution of the disease was the most represented (65.4\%). Haemorrhoidal disease is a common disorder seen mainly in actively producing people (young adult) with a male predominance.

\section{Keywords}

Haemorrhoidal Disease, Anal Event, Cotonou

\footnotetext{
${ }^{*}$ Corresponding author.
}

How to cite this paper: Sehonou, J., Wanvoegbe, F.A., Kpossou, A.R., Agbodande, K.A., Dah-Bolinon, R., Azon-Kouanou, A., Zannou, M. and Houngbe, F. (2015) Haemorrhoidal Disease in Cotonou: Epidemiological, Clinical and Anuscopic Aspects. Open Journal of Gastroenterology, 5, 77-82. http://dx.doi.org/10.4236/ojgas.2015.57013 


\section{Introduction}

Haemorrhoidal disease is the disorder most frequently encountered in proctology [1]. It means all conditions resulting from the progressive expansion or rupture of haemorrhoidal venous plexus. Its pathophysiology remains incompletely elucidated and its preventive and curative treatment is not entirely satisfactory in all patients [2]. Its pathogenesis is very complex, involving many factors. Multiple triggers usually mechanical, inflammatory or metabolic are distinguished. Among the contributing factors and apart from heredity, we have some aggravating conditions. These are sedentary lifestyle, disorders of transit type like diarrhoea or constipation, consumption of spices or alcohol, prolonged sitting and standing stations and pregnancy [3]-[6]. While remained untreated, it can progress to complications (haemorrhoidal thrombosis, haemorrhoidal prolapsis).

The medical treatment is the first-line one when uncomplicated haemorrhoids are occurring (bleeding and/or prolapsis). The epidemiology of haemorrhoidal disease is relatively well documented in developed countries where it appears to be the most common disease of the terminal bowel [7] [8]. In Benin, a retrospective study conducted in 2010 showed that 8.7 cases of haemorrhoidal diseases were admitted annually in visceral surgery consultation [9]. The scarcity of scholar work and especially the absence of our data, a prevalence study of this disease in our country, has led us to undertake this study which objective was to determine the epidemiological, clinical and anuscopic haemorrhoidal disease in Cotonou.

\section{Methods}

This was a cross sectional, descriptive and prospective study covering a three-month period from 06 January 2014 to 10 April 2014. It involved patients seen in gastroenterology consultation in internal medicine of the National Teaching Hospital of Cotonou and in the digestive diseases Unit of the Hospital of Menontin.

The study included patients admitted in consultation for hepato-gastroenterology of the above-mentioned centers. Were included all patients seen in consultation for hepato-gastroenterology during this study period, aged 18 or older (adult subjects) and who have given their consent to participate in this study.

The number of patients included and calculated with the Schwartz was 177 patients. But in total we selected 182 patients. Each patient underwent a clinical and proctology examination by hepato-gastroenterologists. Data were coded and stored by using EPI DATA. The data analysis was made by EPI DATA.

\section{Results}

\subsection{Characteristics of the Study Population}

Of the 182 subjects surveyed those aged 38 - 48 were the most represented with a proportion of $24.7 \%$. The average age was 43 years with extremes of 18 and 85 years.

The proportion of female patients was equal to that of males, a sex ratio of 1 .

\subsection{Epidemiological Aspects of Haemorrhoidal Disease}

Of the 182 patients, 57 had haemorrhoidal disease with a prevalence of $31.3 \%$.

Of the 57 identified cases of haemorrhoidal disease, we recorded 50 cases of internal haemorrhoidal disease, a proportion of $87.7 \%$; 5 cases of external haemorrhoidal disease, $8.8 \%$ and 2 cases of mixed haemorrhoid disease (An association of internal and external haemorrhoid), of 3.5\%.

Of the 57 sick patients, there were 30 men, a slight male predominance with a proportion of $52.6 \%$ and a sex ratio of 1.1. Subjects aged 38 - 48 years were more represented, with a proportion of $28.1 \%$; the average age of patients was 43 years. Of the 57 subjects with haemorrhoidal disease, 38 patients (66.7\%) spent more time in sitting position (more than half of the day). The workers (civil servants, traders and workers) were the majority (75.4\%).

\subsection{Clinical Aspects}

As medical history, $24.6 \%$ of these patients with haemorrhoidal disease were hypertensive. Diabetes, gastric or duodenal ulcer, hepatitis B and hemoglobinopathies SS were each represented in the same proportion of $1.8 \%$. A family history of haemorrhoidal disease was found in $40.4 \%$ of these patients.

Of the 27 women, two (02) 7.4\% had submitted their first haemorrhoidal crisis during pregnancy and four (04) 
cases, $14.8 \%$ had presented their first haemorrhoidal crisis in childbirth.

Chronic constipation was observed in $68.4 \%$ of patients. Table 1 shows the distribution of subjects according to the occurrence circumstances of haemorrhoidal disease.

Of the 57 ill patients, 31 were complaining of rectal bleeding, a proportion of $54.4 \%$. Table 2 shows the distribution of patients according anal manifestations (functional symptoms). 37 had reported two or more functional combination signs, a proportion of $64.9 \%$.

The mean duration of disease was 15 months with extremes of 00 months and 660 months (55 years).

Among the 57 sick patients, 40 had a sawgrass on physical examination, a proportion of $70.2 \%$. Thrombosed external haemorrhoids were 2 patients (3.5\%). We noted a haemorrhoidal disease and anal fissure association in five (05) of our patients, a proportion of $8.8 \%$.

\subsection{Anuscopic Aspect of Haemorrhoidal Disease}

Of the 52 cases of internal and mixed haemorrhoid disease (50 cases of internal haemorrhoidal disease and 2 cases of mixed haemorrhoidal disease), 34 patients were in stage 2 of the haemorrhoidal disease, a proportion of $65.4 \%$. Figure 1 shows the distribution of sick patients according to the stage of internal haemorrhoidal disease.

In our study, two (02) cases of polyp of the anal tube were identified, a proportion of $1.10 \%$ of the study population.

\section{Discussion}

In our study, the prevalence of the haemorrhoidal disease was 31.3\%. This prevalence is above that obtained in Cameroon by Kob Ye Same D. [7], of 10.7\%. On the contrary, it is less than that obtained in Ivory Coast (73\%) by Assi C et al. [10]. The difference between our results and those of these authors could be explained by the differences in patients recruitment method in these studies.

Among the two types of haemorrhoidal disease, the internal was the most dominant in our study with a proportion of $87.7 \%$. This value is similar to that of N'dri N. et al. [11] (84.5\%) in Ivory Coast, but significantly exceeds those obtained by Sangare Mali D. [12] (18.27\%) and M.L. Dicko [13] (21.4\%). It is clear from these studies that the internal haemorrhoidal disease is the most common form of the haemorrhoids. This observation

Table 1. Distribution of patients according to the occurrence circumstances of haemorrhoidal disease.

\begin{tabular}{ccc}
\hline Circumstance: & Number (n) & Percentage (\%) \\
\hline Pregnancy & 02 & 3.5 \\
Fatty meal & 02 & 3.5 \\
Spicy meal & 04 & 7.0 \\
Childbirth & 04 & 7.0 \\
Meat abus & 04 & 7.0 \\
Constipation & 39 & 68.4 \\
Diarrhoae & 01 & 1.8 \\
Starchy eating & 01 & 1.8 \\
Total & $\mathbf{5 7}$ & $\mathbf{1 0 0 . 0}$ \\
\hline
\end{tabular}

Table 2. Distribution of subjects according anal ailing events.

\begin{tabular}{ccc}
\hline Anal Manifestations & Number (n) & Percentage (\%) \\
\hline Rectal bleeding & 31 & 54.4 \\
Anal itching & 02 & 3.5 \\
Anal pain & 17 & 29.8 \\
Anal swelling & 04 & 7.0 \\
Haemorrhoidal prolapsis & 03 & 5.3 \\
Total & $\mathbf{5 7}$ & $\mathbf{1 0 0 . 0}$ \\
\hline
\end{tabular}




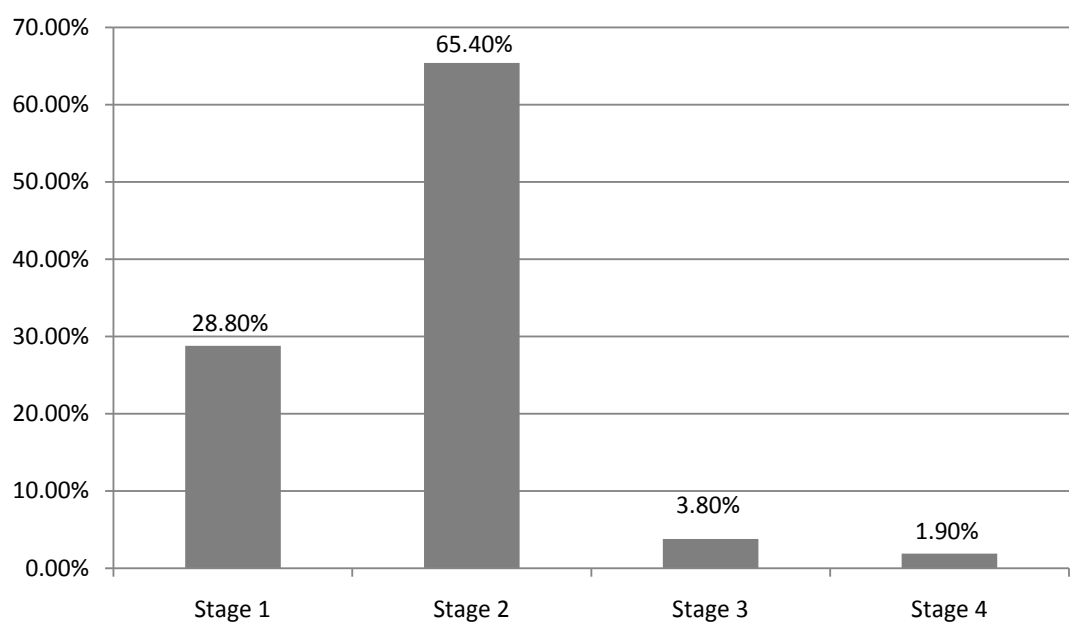

Figure 1. Distribution of patients according to the stage of haemorrhoidal disease.

was also made by Klotz et al. [14] in Gabon.

Our study revealed a male predominance (52.6\%) with a sex ratio of 1.10; what had been reported in studies conducted in Mali by Ele, N. et al. [15] (sex ratio: 1.8) and Pigot, F. et al. [16] (sex ratio: 1.10). This male ratio was even more remarkable in other studies, such as those of: Houézé R.G.C. [17] in Benin in 2006 (sex ratio: 2.5); Gnakadja, N.G. [9] in Benin in 2010 (sex ratio: 2.6); Dicko, M.L. [13] in Mali in 2007 (sex ratio: 2.94). On the contrary, G. d'Agostino et al. [18] in Italy in 2000, Slawik, S. et al. [19] in England in 2007 had found a female predominance with a sex ratio respectively of 0.8 and 0.6 . This male predominance noted in Africa and noted in our study could be due to socio-cultural factors, customs and decency facing the female making the difficult proctology consultations especially by male doctors.

The average age of our patients was 43 years with extremes of 18 and 88 years. The average age is identical to that obtained by Hrora, A. et al. [20] in 2002 in Morocco. In general, it is quite close to the literature: Lohsiriwat Lohsiriwat D. and V. [21]: 44.4; Gnakadja NG [9]. In Benin 40.5 years; Sangare D. [12] in Mali: 40.9 ans.

The isolated rectal bleeding was the most dominant symptom (31 cases, 54.4\%), followed by anal pain (17 cases, 29.8\%). This result meshed very well with the literature which reported a prevalence of rectal bleeding in the symptoms of haemorrhoidal disease: Pigot et al. [16] (56\%) and Sangare D. [12] (75.3\%).

But this result was much lower than those found by Pravin J et al. [22] (96\%) and Habr-Gama A et al. [23] (93.2\%). For Jean et al. [24] the frequency of rectal bleeding increases with size haemorrhoidal packages. On the contrary, for authors such as: Gnakadja, N.G. [9] Houezé, R.G.C. [17] M.L. Dicko, [13] and G. Diallo, et al. [25], anal pain is the most dominant symptoms with proportions respectively $79.6 \%, 75.3 \%, 77.3 \%$ and $85.5 \%$.

Among the 27 women in our series, two (02), 7.4\% had presented their first haemorrhoidal crisis during pregnancy and four (04) 14.8\% had presented their first haemorrhoidal crisis after childbirth. Pregnancy and childbirth are thus factors of first haemorrhoidal crisis in $22.2 \%$ of our patients. Our results were slightly higher than that of Gnakadja, N.G. [9] who found $8.3 \%$ and $4.2 \%$ of patients with haemorrhoidal crisis made in their first postpartum respectively and during pregnancy.

Abramowitz et al. [26] in France had reported that 7.9\% of women in their series had presented a haemorrhoidal thrombosis during pregnancy and $20 \%$ had presented it during the postpartum period. Furthermore, Ansara D et al. [27] in Canada had stated in their study by reporting vaginal-assisted births increased the risk of haemorrhoidal disease while in the caesarean decreased. This could be explained by the increase in intra-abdominal pressure during vaginal deliveries.

In our study, we observed an association of haemorrhoidal disease and anal fissure in five (05) of our patients, a proportion of $8.8 \%$. This same observation was made by Assi, C., et al. [10] (17 cas, or 23.3\%). Gnakadja, N.G. [9] and Sotoudehmanesh, R., et al. in 2007 [28] in their series (100 and 87 patients respectively), had made the same remark with respective frequencies of $28.7 \%$ and $26.9 \%$ which was significantly higher than that we got. This difference in proportion noted, would be due to the smaller size of our sample. This association is a real problem in patients who have the fear of an upcoming defecation and therefore delay the act, thus encouraging faecal stasis and constipation [29]. 
Pure internal haemorrhoidal disease was the most dominant with a proportion of $87.7 \%$ (50 patients). The association internal-external haemorrhoidal disease was found in 2 patients. Thirty-four (34) of these patients were in stage 2 of the internal, meaning a proportion of $65.4 \%$. This result is comparable to that found by Kob Ye Same D. [7] (42.2\%) by D. Sangare [12] in his series, had obtained a predominance of stage I (51.7\%), while in their studies Pigot, F. et al. [16], Dicko, M.L. [13] and Dembélé K.S. [6] stages 3 and 4 were the most observed in $94 \%$ respectively; $62.7 \%$ and $97.5 \%$ of cases. These differences may be rooted in the method of recruitment and the type of service where the study was conducted (medicine and surgery).

\section{Conclusion}

Haemorrhoidal disease is relatively common in our study (31.3\%). The symptoms were dominated by rectal bleeding. Internal haemorrhoids were the most common type (87.7\%) with usually a haemorrhoid prolepsis, stage 2 (65.4\%). It must therefore be systematically sought in consultation because of underreporting.

\section{References}

[1] Traore, A., Diake, I., Togo, A., et al. (2010) Hemorrhoidal Disease in the General Surgery Department of CHU Gabriel Toure. Médecine d'Afrique Noire, 57, 358-362.

[2] Zeitoun, J.D. and De Parades, V. (2011) Why an Issue Paper on the Hemorrhoidal Disease? La Presse Médicale, 40, 918-919. http://dx.doi.org/10.1016/j.lpm.2011.06.016

[3] Watson, S.J. and Phillips, R.K.S. (1996) Hemorrhoidectomy: Current Status. Der Chirurg, 67, 213-221.

[4] Godeberge, P. (2001) Hemorrhoids Treatment: Longo Intervention versus Endoscopic Treatment. Journal Canadien de Chirurgie, 138, 1-13.

[5] Fabien, D. and Bigard, M.A. (2005) Hemorrhoidal Disease. Rev du Praticien, 55, 1719-1722.

[6] Dembele, K.S. (2010) Study of the Hemorrhoidal Disease in the General Surgery Department of the Hospital Somine Dolo Mopti. Ph.D. Dissertation, University of Bamako.

[7] Kob Ye Same, D. (2009) Clinical and Epidemiological Aspects of the Hemorrhoidal Disease in Urban Adults in Douala. Ph.D. Dissertation, University of Yaounde I.

[8] Gawenda, M. and Walter, M. (1996) Surgical Treatment of Advanced Hemorrhoids-Is It an Intervention on Daily Basis Surgical? Der Chirurg, 67, 940-943. http://dx.doi.org/10.1007/PL00002542

[9] Gnakadja, N.G. (2010) Epidemiological, Diagnostic and Therapeutic Aspects of the Hemorrhoidal Disease in University Clinics of Visceral Surgery “A” and “B” in CNHU-HKM. Ph.D. Dissertation, UAC-FSS, Cotonou.

[10] Assi, C., Soumare, G., Kone, S., et al. (2012) Prevalence of Hemorrhoids and Anal Fissure in the Etiology of the Inaugural Proctalgia at the University Hospital (CHU) in Cocody (Ivory Coast). Mali Médical, 27.

[11] N’dri, N., Kouakou Lohoues, M.J., Attia, K.A., et al. (1994) Hemorrhoidal Disease in African Hospitals: About 522 Cases Collected at the University Hospital of Cocody. Médecine et Chirurgie Digestives, 23, 233-234.

[12] Sangare, D. (2008) The Internal Hemorrhoidal Disease in the Digestive Endoscopy Center CHU Gabriel Toure and Medical Offices. Ph.D. Dissertation, University of Bamako, Bamako.

[13] Dicko, M.L. (2007) Study of the Hemorrhoidal Disease in the General Surgery Department at CHU Gabriel Toure. Ph.D. Dissertation, University of Bamako, Bamako.

[14] Klotz, F., Moussavou, J.B., Walter, P. and Nguemby-Mbina, C. (1988) Rectosigmoidal Pathology in Equatorial Africa: Etiological Approach in the Gastrointestinal Endoscopy Department of the CHU of Libreville-Gabon. Afr Med Santé, 17, 277-279.

[15] Ele, N., Okiemy, G., Chocolat, R., et al. (2007) Results of Surgical Treatment of Hemorrhoidal Disease Using the Technique of Milligan and Morgan. About 56 Cases (CHU Brazzaville). Mali Medical, 22, 58-60.

[16] Pigot, F., Siproudhis, L. and Allaert, F.-A. (2005) Risk Factors Associated with Haemorrhoidal Symptoms in Specialized Consultation. Gastroentérologie Clinique et Biologique, 29, 1270-1274. http://dx.doi.org/10.1016/S0399-8320(05)82220-1

[17] Houeze, R.G.C. (2006) Support for Non-Tumor Anorectal Disorders in Visceral Surgery “A” CNHU-HKM Cotonou. Ph.D. Dissertation, UAC-FSS, Cotonou.

[18] D’Agostino, G., Zampogna, A., Rognoni, M., Ricci, A. and Garavoglia, M. (2000) Hemorrhoidectomy in MucoHemorrhoidal Prolapse Using Mechanical Stapler. Minerva Chirurgica, 55, 395-399.

[19] Slawik, S., Kenefick, N., Greenslade, G.L. and Dixon, A.R. (2007) A Prospective Evaluation of Stapled Haemorrhoidopexy/Rectal Mucosectomy in the Management of 3rd and 4th Degree Haemorrhoids. Colorectal Disease, 9, 
352-356. http://dx.doi.org/10.1111/j.1463-1318.2006.01163.x

[20] Hrora, A., Raiss, M. and Menfaa, M. (2002) Hemorrhoidectomy by the Technique of Milligan and Morgan (About 200 Cases). Maroc Médical, 24, 8-10.

[21] Lohsiriwat, D. and Lohsiriwat, V. (2005) Out Patient Hemorrhoidectomy under Perianal Anesthesics Infiltration. Journal of the Medical Association of Thailand, 88, 1821-1824.

[22] Pravin, J. and Gupta, B. (2005) Novel Approach to Advanced Hemorrhoidal Disease. Romanian Journal of Gastroenterology, 14, 361-366.

[23] Habr-Gama, A., Esous, A.H., Roveló, J.M., Souza, J.V., Benício, F., Regadas, F.S., et al. (2003) Stapled Hemorrhoidectomy: Initial Experience of a Latin American Group. Journal of Gastrointestinal Surgery, 7, 809-813. http://dx.doi.org/10.1016/S1091-255X(03)00102-1

[24] Gravié, J.F., Lehur, P.-A., Huten, N., Papillon, M., Fantoli, M., Descottes, B., et al. (2005) Stapled Hemorrhoidopexy versus Milligan-Morgan Hemorrhoidectomy. Annals of Surgery, 242, 29-35. http://dx.doi.org/10.1097/01.sla.0000169570.64579.31

[25] Diallo, G., Sissoko, F., Maiga, M.Y., et al. (2003) Hemorrhoidal Disease in the Surgical Department B of Hospital Point G. Mali Medical, 1, 9-11.

[26] Abramowitz, L., Sobhani, I., Benifla, J.L., Vuagnat, A., Daraï, E., Mignon, M. and Madelenat, P. (2002) Anal Fissure and Thrombosed External Hemorrhoids before and after Delivery. Diseases of the Colon \& Rectum, 45, 650-655. http://dx.doi.org/10.1007/s10350-004-6262-5

[27] Ansara, D., Cochen, M.M., Gallop, R., Kung, R. and Schei, B. (2005) Predictors of Women’s Physical Health Problems after Childbirth. Journal of Psychosomatic Obstetrics \& Gynecology, 26, 115-125. http://dx.doi.org/10.1080/01443610400023064

[28] Sotoudehmanesh, R., Ainechi, S., Asgari, A.A. and Kolahdoozan, S. (2007) Endoscopic Lesions in Low-To AverageRisk Patients with Minimal Bright Red Bleeding from Midline Anal Fissures. How Much Should We Go in? Techniques in Coloproctology, 11, 340-342. http://dx.doi.org/10.1007/s10151-007-0377-3

[29] Abromowitz, L. and Batallan, A. (2003) Epidemiology of Anal Lesions (Cracks and External Hemorrhoidal Thrombosis) during Pregnancy and the Postpartum Period. Gynécologie Obstétrique et Fertilité, 31, 546-549. 